To cite this article: Mandu A. March, Hannah A. Vaikosen and Enye A. Akporoghene (2020) Information Needs and Seeking Behaviour of Nurses at Rivers State University Teaching Hospital, Port-Harcourt. Information Impact: Journal of Information and Knowledge Management, 11:3, 63-74, DOI: /dx.doi.org/10.4314/iijikm.v11i3.7

To link to this article https://dx.doi.org/10.4314/iijikm.v11i3.7

\title{
Information Needs and Seeking Behaviour of Nurses at Rivers State University Teaching Hospital (RSUTH), Port-Harcourt
}

\author{
${ }^{1}$ Mandu A. March, ${ }^{2}$ Hannah A. Vaikosen and ${ }^{3}$ Enye A. Akporoghene \\ ${ }^{1}$ Bayelsa State College of Health Technology, Otuogidi-Ogbia \\ ${ }^{2}$ Niger Delta University, Amasoma Wilberforce Island, Bayelsa State \\ ${ }^{3}$ Port-Harcourt Literary Society Library, Rivers State
}

\section{Abstract}

The study investigated information needs and seeking behaviour of nurses at Rivers State University Teaching Hospital (RSUTH), Port Harcourt. It adopted a descriptive research survey. The population of the study was 352 nurses at RSUTH from which a sample 100 was drawn. Self-structured questionnaire was used. The questionnaire included a four point likert scale (4-1). Out of 100 copies of the questionnaire administered, 94 were found valid for analysis. Data was analysed using simple percentages and mean score. The findings of the study showed that nurses needed information on drugs therapy, diagnostic, patients' management and personal development. The factors that motivated their information seeking include working environment, patients' care, professionalism and personal development. To satisfy their curiosity, they consulted different sources of information including colleagues, internet and textbook. It also showed that nurses had a negative perception about library and information services in meeting their information needs. Inadequate information resources in the library, inadequate information retrieval skills and closed access were some of the challenges they faced when seeking for their information needs. However, they suggested training of nurses and provision of standard library for the nurses. It was recommended among other things that the library should be well equipped to meet the information needs of the nurses also the nurses should acquire information retrieval skills to enable them access information resources on the internet and databases.

Keywords Information needs, Information seeking behaviour, Nurses, Rivers, Health information

CONTACT Mandu A.March, Hannah A.Vaikosen and Enye A. Akporoghene cassandreaenye@gmail.com Bayelsa State College of Health Technology,Otuogid-Ogbia, Niger Delta University, Amasoma, Wilberforce Island, Bayelsa and Port-Harcourt Literary Society, Port-Harcourt. 2020 The Authors Published with License by Information Impact 


\section{Introduction}

Information is an essential commodity for human development. As a processed data from which meaning may be deduced from, it is important for planning, decision making and reduction of uncertainty. The present environment of information is influenced and associated with a number of information sources made available in systems whereby humans and computers can interface. Information is vital to survival and decision making at every stage of human endeavour because it furnishes an individual with facts, experiences, procedures and processes to follow in actualizing a plan. Every human therefore, needs information for progress, decision making, professionalism, expertise, practices and effective services delivery. Information need according to Adebayo, Akanni and Busuyi (2017) is an individual or group's desire to detect and acquire information to satisfy both conscious and unconscious needs. It is the availability of different sources of information, individual characteristics, trend, career, profession and environment in which one operates, influences and exposes nurses to different information seeking behaviour. Iota, Azuma and Nishimura (2017) opined that Information-seeking behavior significantly differed with respect to qualification, institution where basic education was received, job ranking, a form of employment and the environment in which Information and Communication Technology (ICT) was used. They further stated that, it is necessary to create environments that facilitate information seeking for nurses in various departments, and to implement adequate information literacy education in order to support information-seeking behaviour of nurses.

Information seeking behaviour is as old as man because man since inception has been making inquiry into the problem that confronts him. Different approaches were employed and different sources were consulted when making inquiry to satisfy his curiosity or information needs. But for Bruce, Ford, Case and Given (as cited in Makinde, Jiyane \& Mugwisi, 2019) stated that the study of information behavior has developed since its inception during the 1960s when most research was geared towards understanding how professionals sought for information and the sources they consulted. Information seeking behaviour is the processes of recognizing the need for information, searching for, using, and sharing it. It is usually associated with information search behaviour, information retrieval behaviour and information literacy skills.

Eftekhar and Hayati (2016) observed that information seeking behaviours exhibited by information users are derived from users 'information needs when they have the urge for information. In the opinion of Azadeh and Ghasemi (2016) researchers may apply different techniques to collect information which are basically influenced by different factors, and consequently, researchers will express different information-seeking behaviours.

Nurses need to seek information vastly due to their professional activities. They work with doctors and other health care workers to make patients well and to keep them fit and healthy. Nurses may be differentiated from other health care workers by their training, scope of practice, and approach to patient's care. Nurses perform several functions such as recording patient's medical histories, perform diagnostic tests and operation, analyze results of the test, give treatment based on the results of the test, care for nursing mothers, operate medical machinery as well as follow up on patients to ensure patients' recovery. They also caution the public on early signs and symptoms of diseases, outbreak of diseases, diet taking and nutrition, exercise and keeping fit. Nurses observe the patients behaviour and record their observations. Nurses are counselors. They form the majority of clinical employees of hospitals and they are consulted more than other health workers. Caring for patients and performing professional roles may pose a lot of challenges because they deal with human life, and as a result they will have to show some high level of professionalism and expertise when handling a patient especially a severe case. This will 
require nurses to prepare and keep informed on the ethics and trends in the the profession. To achieve this they may consult several databases relevant to their profession such as Pubmed, HINARI,MEDLINE, medical record, etc. In addition they may also consult the social media, textbooks and the library. Nurses who are new to the profession may rely so much on colleagues, supervisors for decision making due to the level of experience and expertise their colleagues' especially senior colleagues or supervisors may offer. Anyanwu, Oparaku and Benson (2016) found that nurses consulted Internet, Journals, books and other medical database when seeking for their information needs. Nurses' information behaviour therefore include all the behaviours nurses exhibit when identifying, gathering, processing and managing information for effective work performance. Pajarillo (as cited in Nwagwu and Oshiname, 2009) identified two important elements describe such information behaviour as nurses' information needs and the sources of information that they prefer and use. It can therefore be stated that nurses information needs can be ascertained by their information needs which studies have shown to include; to be abreast of new developments in the field of nursing, medications, patient care technique, drug therapy, diagnostic, outbreak of diseases, etc as well as the sources of information they consult which authors have identified to include colleagues, internet, medical record, databases, textbook, journals, library, etc. The study therefore investigate information needs and seeking behaviour of nurses at Rivers State University Teaching Hospital (RSUTH), Port Harcourt

\section{Brief History of Rivers State University Teaching Hospital, Port Harcourt}

Rivers State University Teaching Hospital (RSUTH) formerly known as Braithwaite Memorial Specialist Hospital (BMSH) is a government owned hospital, named after Eldred Curwen Braithwaite, a British doctor. It is located in old GRA, Rivers State a neighbourhood of Port Harcourt and is operated by Rivers State Hospital Management Board. It was established in March 1925 as Braithwaite Memorial Hospital and originally served as a medical facility for senior civil servants. It later became a General Hospital and has since gained status as a "Specialist Health Institution. In 2018, it was renamed to serve as a Teaching Hospital for the state owned university following the establishment of college of medical sciences officially recognized by theFederal Ministry of Health. The facility has 375 licensed beds and 731 medical staff members. Its departments include Medicine, Paediatrics, Laboratories, Radiology, Family Medicine, Obstetrics and Gynaecology, Anaesthesia, Surgery, Pathology, Ophthalmology, Accident Centre and the Surgical/Medical Emergency. Some other departments are Pharmacy, Finance, Maintenance and General Administration.

\section{Statement of the Problem}

Nurses comprise most of emergency clinical workers, and the most habitually counseled asset people in the human services framework. Nurses are liable for not just actualizing doctors' and specialists' clinical requests or medicines, they keep up a consistent record over their patients' wellbeing. Nurses care for the sick and furnish them with physical and psychosocial needs, until they recover their past condition of health. They collect and transmit data from patients and the patients' families to other health care providers, and are liable for organizing all consideration exercises for patients in their consideration. Information is in this manner a vital device for medical attendants, and how they obtain and utilize the information are key determinants of their performance because information seeking behaviour encompasses nurse's approaches to express information needs, seek information, evaluate, select and finally put to use. However several sources of information are available for nurses to consult in order to improve on their work but despite the vast availability of information sources, observations have shown that nurses at RSUTH seem to lack information to fully exploit their work activities. This could be 
attributed to their inability to seek for their information needs. It is against this backdrop that the study sought to investigate the information needs and seeking behaviour of nurses at RSUTH.

\section{Objectives of the Study}

The main objective of the study is to determine the information needs and seeking behaviour of nurses at the Rivers State University Teaching Hospital, Port Harcourt. The specific objectives are to:

- identify the factors influencing the information needs of nurses at RSUTH

- unravel nurses perception on library and information services.

- find out the challenges facing nurses seeking for information

- discover the strategies to improve access to information

\section{Research questions}

- what are the factors influencing the information needs of nurses at RSUTH?

- what are the perception of nurses on the role of library in the provision of their information needs?

- what are the challenges facing nurses when seeking for information needs?

- what are the strategies to improve nurses' access to information

\section{Literature review}

Nurses need information for various purposes. They need health information to enable them perform their job effectively. Health information need is essential for the nurses to deliver their jobs effectively and efficiently. They need information on surgical operations to enhance surgical procedures, they need information on current trends in their profession to keep abreast of any changes in the practices in the nursing profession. They also need information on medication, relevant database, drug therapy, diagnostic,

Turner, Stavri, Revere and Altimore (2008) studied information needs and resources of public health nurses in a local health department. The population comprised seventeen public health nurses at a local public health department in Oregon. Semi structured in-depth interview was conducted. The study was analyzed using a constant comparative method to assess the information nurses sought and used in their work. It was discovered that the information needs of the nurses differed according to employees' position and roles. However, Anyanwu, Oparaku and Benson (2016) in their own study on information needs of Nurses for effective health care delivery in Nigeria with Federal Medical Centre, Owerri. Descriptive survey method was adopted with a population of 300 from Federal Medical Centre, Owerri and the sample size of 171. The questionnaire was used as instrument form data collection. The data was analysed using the simple percentages and tables. It was found that nurses needed information to care and manage patients as well as to improve their knowledge in clinical areas.

Asl, Ghasemi, Gharibvand \& Malehi (2017) carried out a study on the information seeking behavior and information needs of nurses at Ahvaz hospitals. Descriptive-analytical study was adopted 
with the statistical population of 1246 nurses from which 293 people were selected. Questionnaire was used to gather the data. Validity and reliability of the questionnaire were confirmed by Cronbach's alpha which yielded a coefficient of 0.71 implying that the instrument was reliable. The data was analysed using descriptive statistics. The results showed that most nurses needed information about new developments in their profession. They used simple searching technique to find the required information which aimed to update their information using up-to-date Database.

Nwagwu and Oshiname (2009) carried out a study on the information needs and information seeking behaviour of nurses at University College Hospital, Ibadan and found that $99.5 \%$ of the nurses needed information on outbreak of diseases, new remedies and nursing processes $99 \%$ while $98.5 \%$ needed results of scientific research. The study also showed that general information $(98.5 \%)$ and information about to prevent, avoid contracting HIV/AIDS from patients $(98.0 \%)$ appeared to be of high priority to nurses than economic or business information. Nurses contribute immensely to the lives and healthiness of their patients. Therefore, they should yearn for personal development, professional development, patients' management, drugs therapy, diagnostic, personal hygiene, and outbreak of disease as these will enhance their work related duties.

Several factors may drive information seeking behavior such as Individual's information infrastructure, experience, knowledge, profession, career, age, gender, etc. In the nursing profession, a lot of factors may come into play. For example patients' information needs may influence nurses' information seeking, working environment, work ethics, attitude of colleagues, availability of information sources, trend among others could influence nurses information seeking behaviour. Baro and Ebhomeya (2013) investigated the information needs and seeking behaviour of nurses in selected hospitals in Nigeria. Descriptive research survey was adopted. The population comprised nurses at the Federal Medical Center (FMC), Yenagoa, and Niger Delta University Teaching Hospital (NDU-TH), Okolobiri, in Bayelsa State. It was found that the factors which motivated nurse's information seeking behaiour were to better patient care, improved medication administration, and better job performance. Ota (2017) analyzed the factors that influenced clinical nurses' information-seeking behavior. The population of the study was 324 nurses based on individual characteristics, continuing education factors and environmental factors of Internet usage. It was found that information-seeking behaviour was associated with respect to qualification, institution where basic education was received, job ranking, a form of employment, membership to academic associations, and the environment in which ICT was used. According to them it is necessary to create environment that enhances information seeking for nurses and implement adequate information literacy education in order to facilitate information-seeking behaviour of nurses. Profession, colleagues, and environment normally has a great influence in one's information seeking. The same is applicable to nurses. Furthermore, the sources and availability of information is also an area of concern. Therefore, internet, medical record, books, library, journals, Pubmed, HINARI and Medline and colleagues could influence nurses information seeking.

Information sources could be print resources, non-print resources. Print resources are printed books, journals magazines, etc. Non print resources are information held in media such as sound, visual, graphics, animation, etc. Electronic resources are born digital resources or created digital resources often in electronic form example databases, e-books, e-journals, e-databases etc. Information sources are materials consulted by the information user while seeking information. Information users make active and intentional attempts to seek up to date information from the library, electronic sources and others (Muoekebe, Ezeani \& Nwankwo, 2018). Information sources could equally be categorized as primary, secondary and tertiary sources. A primary source is a firsthand information or an original created by a 
person who may be directly involved in the subject matter. They include fiction, diarie, autobiographies, memoirs, letters, etc. Secondary sources on the other hand are primary sources which have been analyzed, reported, summarized and restructured. They include textbooks, book reviews, dictionaries, encyclopedias, bibliographies, etc. Tertiary sources are secondary sources further processed. Some of the secondary sources also fall under tertiary sources such as bibliography, manuals, library catalogue, etc. Anyanwu, Oparaku \& Benson (2016), showed that information sources consulted by nurses include Internet, journals and books, and other medical database when seeking for their information needs. Saha (2020) Investigated information needs and seeking behaviour of nurses of private hospitals of Bhubaneswar, Odisha. Structure questionnaire was used. Data was analysed in simple percentages and tables. It showed that both print and e-resources were consulted. Among all the sources of information identified by authors, Igwela and Nsirim (2018) opined that the library is the most reliable place where the most desirable information can be sought. Information sources including print, non-print, primary, secondary and tertiary sources can be consulted by nurses. However, with the emergence of ICT, there is a paradigm shift to electronic information sources which has also made provisions for access to various medical databases.

Okiy (2014) defined library as a collection or group of collections of books and other materials organized and maintained for use, reading, consultation study and research. According to Gama (2013) in order to satisfy the informational needs of its users, the university library has to ensure adequate provision of actual information, service, and facilities. Kumar, (2012) found that less than $50 \%$ of the users were satisfied with the collection, physical facilities and more than $50 \%$ satisfied with the information resources and services and functional organization of the libraries. Behaviour of the staff is highly appreciated by most of the respondents. Libraries were a primary resource for evidence-based practice. Marshall (2013) studied the value and impact of library and information services on patient care. The study used focus groups of librarians and a web-based survey of physicians, residents, and nurses at 56 library sites serving 118 hospitals; and 24 follow-up telephone interviews. Survey respondents were asked to base their responses on a recent incident in which they had sought information for patient care. It was discovered that library and information resources were perceived as valuable, and the information obtained was seen as having an impact on patient care. There was a positive perception of the library and information services.

Studies have found the challenges affecting the information seeking behaviour of nurses Anyanwu,Oparaku and Benson (2016) for example found that nurses inadequate training in the use of information resources, lack of access to internet amongst others were the factors militating against easy accessibility of information. Also, Ghasemi, Gharibv and Malehi (2017) found that because the major barrier to update information was shortage of time. Therefore, it is essential to teach information skills to nurses, so that they can access modern and updated information in the field of nursing and obtain the latest information in this field from evidence-based information sources and databases. Muokebe, Enweani, Nwankwo(2018)surveyedthe information needs and seeking behaviour of practising nurses at $\mathrm{O}$ urLady of Lourdes Hospital Ihiala. Nigeria. The population comprised fifty-two (52) practicing nurses in Our Lady of Lourdes Hospital Ihiala. Total enumeration sampling technique was used. Data were collected and analysed using mean scores. Lack of current materials on nursing and lack of information literacy were the most ranking problems of information needs of nurses.

Improving access to information is vital to nurses in performing their duties. Therefore strategies must be put in place in improving access to information. Anyanwu, Oparaku and Benson (2016) found that stocking of medical libraries with current materials on nursing as well as automation of health and 
medical libraries were the strategies for solving the problems of accessibility to health information. Medical libraries should be equipped with adequate and current information to support nurses when seeking their information needs in the library. In addition availability of information, information retrieval skills, power supply and establishment of standard library for the medical practitioners would motivate information seeking of nurses.

\section{Methodology}

The study adopted a descriptive research survey. The population is 362 nurses at the Rivers State University Teaching Hospital, Port Harcourt from which a sample size of Hundred (100) was drawn. Simple random sampling technique was used to select the nurses. Self-structured questionnaire was used. The questionnaire included a four point likert scale (4-1). One hundred copies of the questionnaire were administered within a week and at different shifts, 94 copies of the instrument were found valid for analysis. Data was analysed using simple percentages and mean score. The decision was based on the mean of 2.5, which implies that any item with a mean score of 2.50 and above was accepted while any item with a mean score below 2.5 was rejected.

\section{Results and Discussion}

Fig 1: Information needs of Nurses at RSUTH

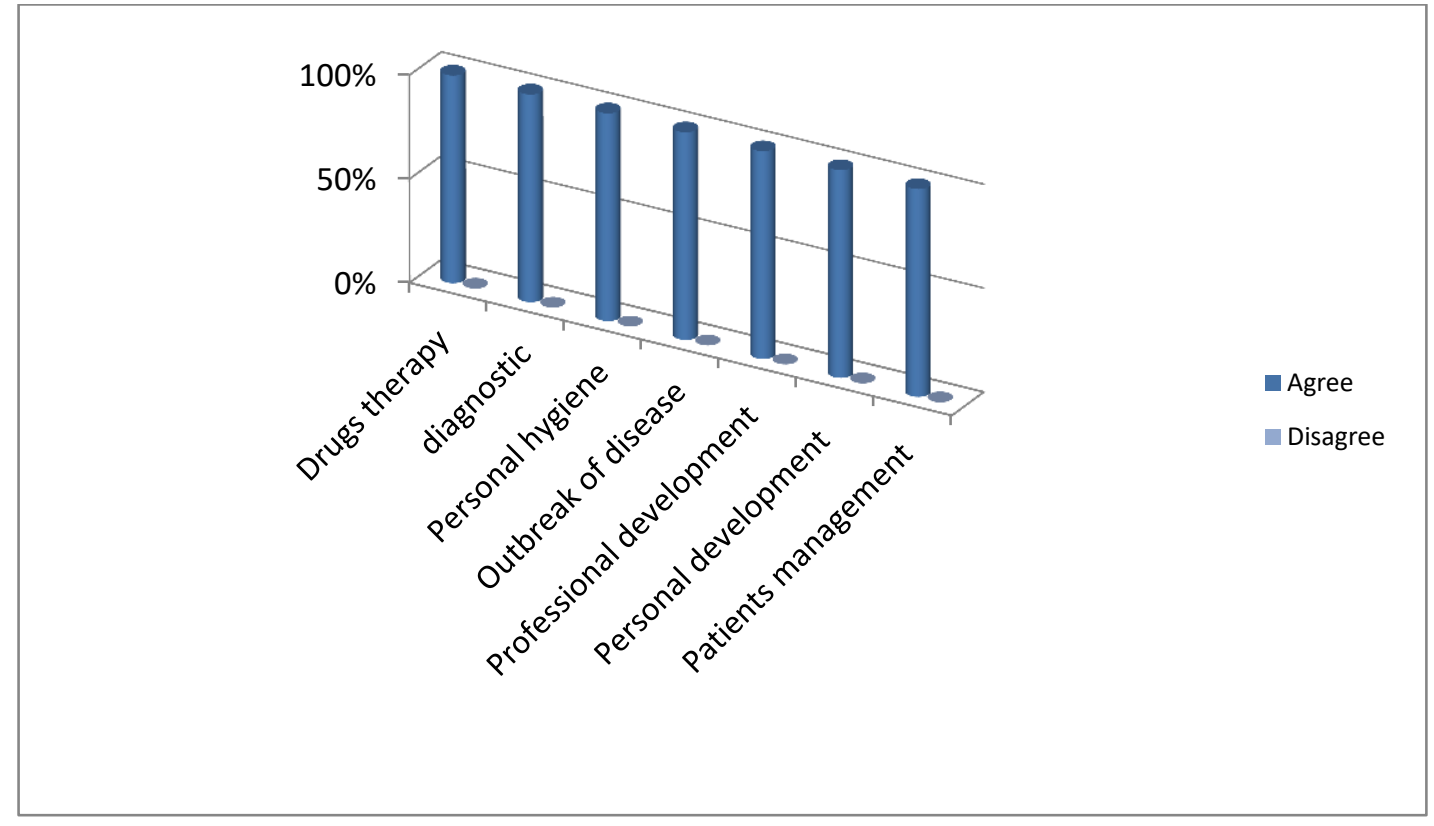

Fig. 1 the information needs of nurses and revealed that all the respondents (100\%) agreed that they needed information on personal development, professional development, patients' management, drugs therapy, diagnostic, personal hygiene and outbreak of disease. The study corroborates with the study carried out by Anyanwu, oparaku and Benson (2016) on meeting the information needs of nurses for effective healthcare delivery in federal medical centre, Owerri, Imo State and found that nurses had need of information to care and manage patients as well as to improve their knowledge in clinical areas. 


\section{Fig.2: Challenges facing nurses when seeking for information needs}

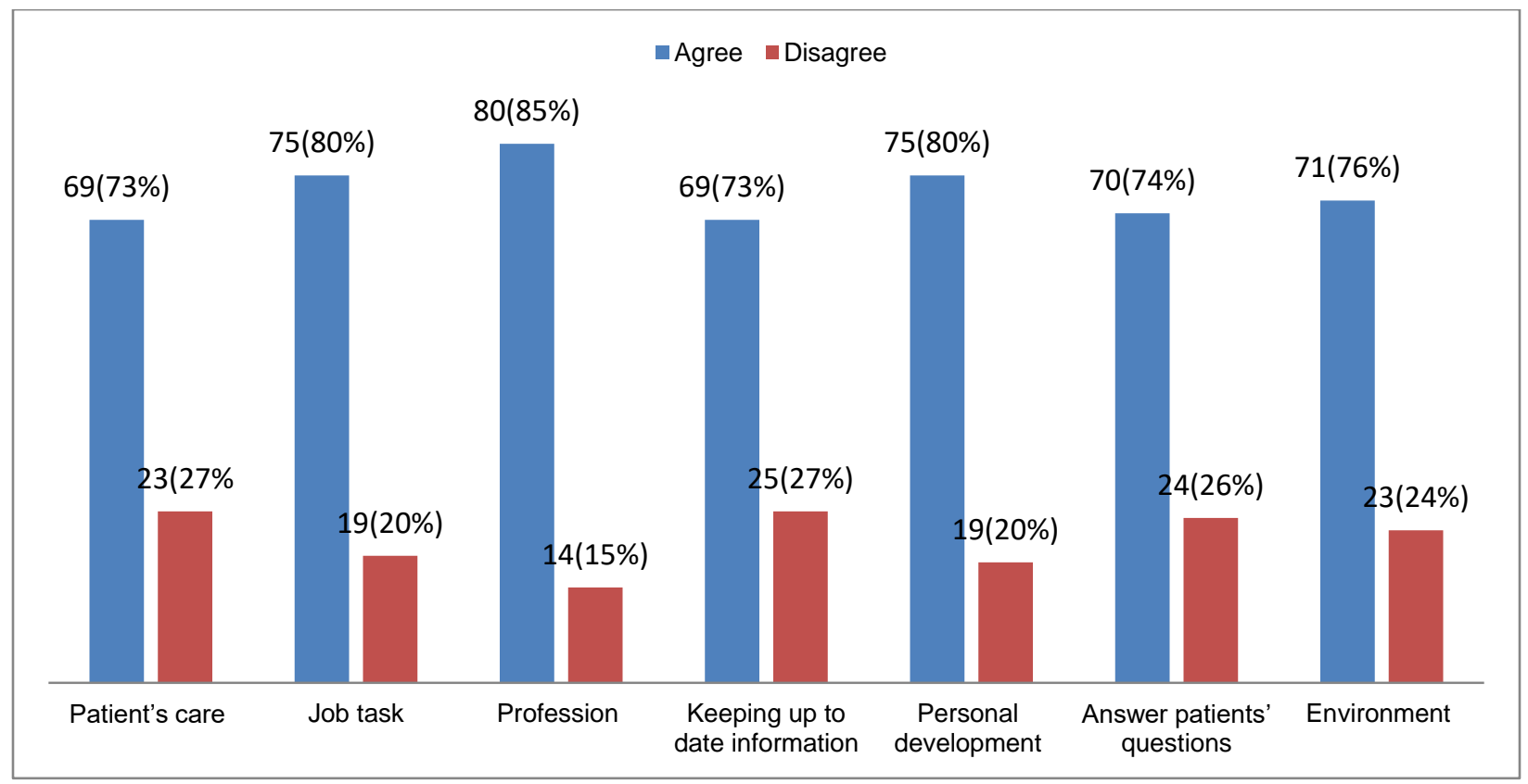

Fig.2 shows that the factors which influenced nurses' information seeking behaviour are profession (85\%), personal development (80\%), job task $(80 \%)$, environment $(76 \%)$, answer patients questions (74\%), patient's care (73\%) and of keeping up to date information (73\%). The study corroborates with the study carried out by Wanyingi (2018) on information needs and seeking behaviour of nursing and clinical students in medical libraries in Aga Khan University and found that the respondents' purpose of seeking information were to answer patients questions, keeping up to date information, improving knowledge on practice.

\begin{tabular}{|c|c|c|}
\hline What sources of information do you consult? & Mean & Decision \\
\hline Medical Record & 3.1 & Agree \\
\hline Pubmed & 1.8 & Disagree \\
\hline HINARI & 1.7 & Disagree \\
\hline MEDLINE & 1.8 & Disagree \\
\hline Internet & 3.2 & Agree \\
\hline library & 2.4 & Disagree \\
\hline books & 2.6 & Agree \\
\hline Journals & 2.4 & Disagree \\
\hline Colleagues & 3.3 & Agree \\
\hline Grand Mean & 2.5 & Agree \\
\hline
\end{tabular}

Table 1 shows the sources of information that nurses consulted and shows that colleagues, internet, medical record and Books had a mean score above the reference mean indicating they were consulted. On the other hand, library, journals, Pubmed, MEDLINE and HINARI had mean scores below the reference mean indicating they were not consulted. The study corroborates with the study carried out by Enwaeni, Nwankwo and Ndidi (2018) on the information needs and seeking behaviour of practicing nurses at Our Lady of Lords Hospital, Ihiala, Nigeria and found that enquiry from colleagues topped the list also, Adebayo, Akanni and Busuyi (2017) on information needs and seeking behaviour of medical students at the college of medicine, University of Ibadan, Nigeria and found that most of the respondents used the Internet (2.81), textbooks (2.75), journals (2.71), communication with Peers (2.59). On the other hand 
Medical CD-ROMS (2.21), Library (2.01), HINARI (1.41) and MEDLINE (1.54) which had mean scores below 2.5 indicated they were not using the sources.

Table 2: Perception about library and information services

\begin{tabular}{lccc}
\hline What are your perception about library resources and services & Mean & Decision \\
& & & \\
\hline Information in the library are current & 2.2 & Negative \\
Information resources in the library are adequate & 2.2 & Negative \\
Library resources will meet my information needs & 2.1 & Negative \\
I am satisfied with library resources and services & 2.0 & Negative \\
The library is a reliable information centre & 3.5 & Positive \\
Grand mean & $\mathbf{2 . 4}$ & Negative
\end{tabular}

Table 3 shows that the only item with a mean score above the reference mean of 2.5 is: the library is a reliable information center, indicating a positive perception. All other items have mean scores below the reference mean indicating a negative perception. Furthermore, The grand mean of 2.4 indicates an overall negative perception of library and information services. This could be attributed to the poor library and information services in the RSUTH.

\section{Fig.3: Challenges facing nurses when seeking for information needs}

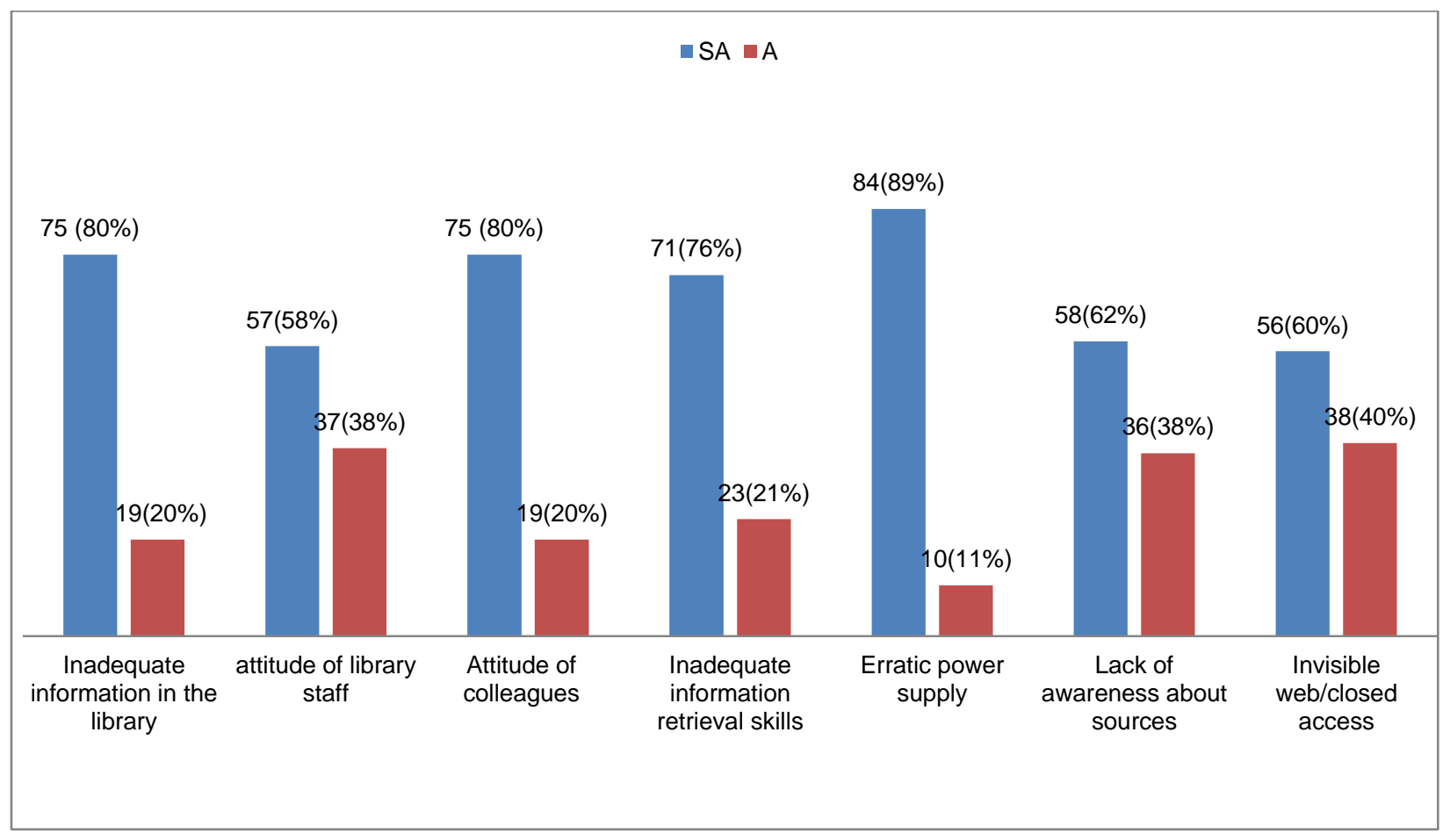

Fig.3 shows that erratic power supply (89\%), attitudes of colleagues (80\%), inadequate information resources in the library (80\%), inadequate information retrieval skills $(76 \%)$, lack of awareness about 
sources $(62 \%)$, invisible web/closed access $(60 \%)$ and attitudes of library staff(58\%) were the challenges that faced nurses when seeking of information. The study is in line with that of Muokebe, Enweani, Nwankwo (2018) who found lack of current materials on nursing and lack of information literacy were the most ranking problems of information needs of nurses.

Fig. 4: Strategies on improving access to information

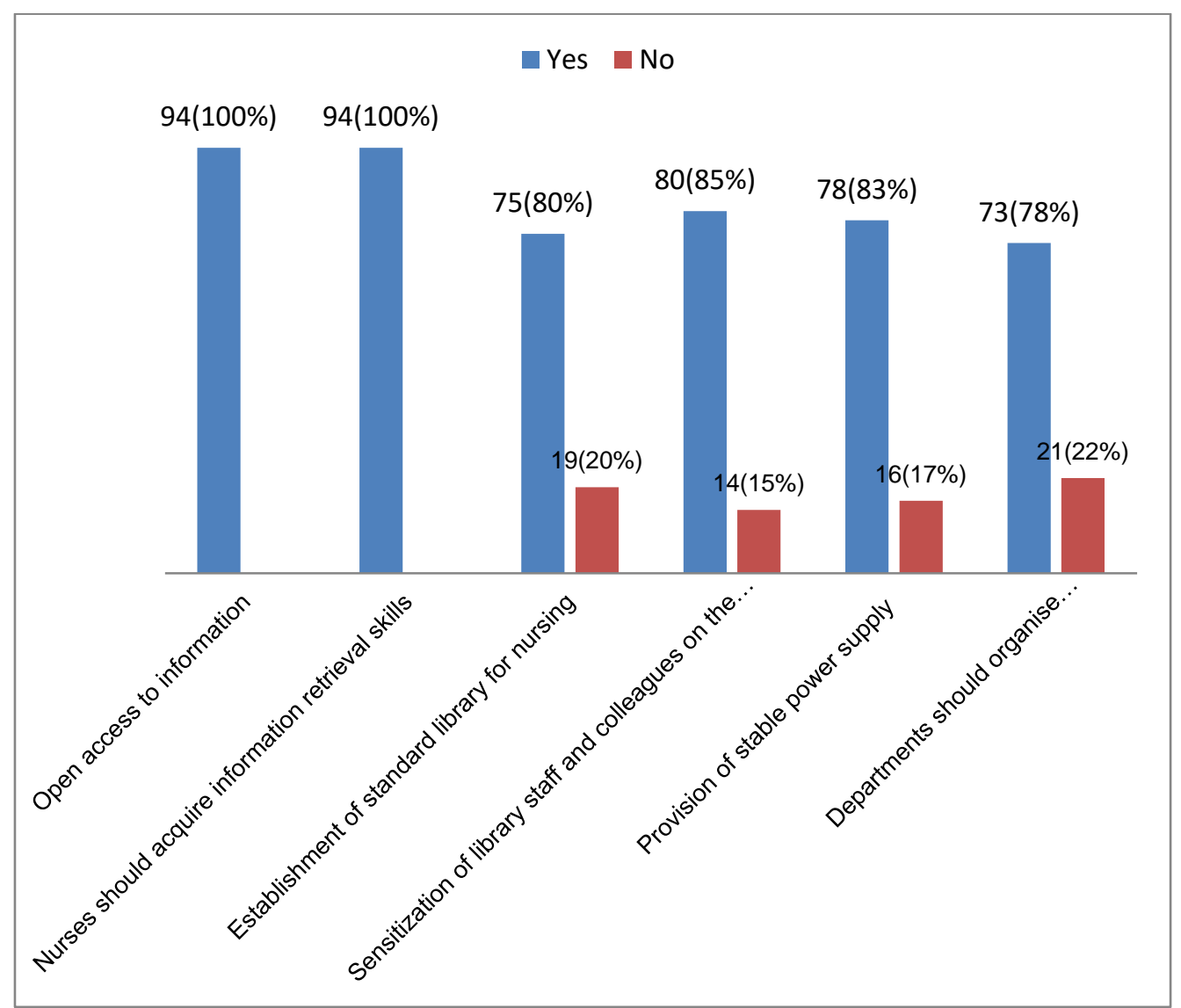

According the finding in fig.4 nurses suggested that open access (100\%), information retrieval skills (100\%), sensitization of library staff and colleagues for information provision (85\%), provision of stable power supply (83\%), organizing seminar/workshop/ conferences regularly (78\%) and establishment of standard library $(76 \%)$ would improve access to information. The study is in line with that of Nwagwu and Oshiname (2009) who found the suggestion of nurses for improving their access to information to include department seminars, nurses should be computer literate, establishment of information centres/libraries among others.

\section{Conclusion}

Nurses examine symptoms, take record of patient's medical histories, conducts and records test results, diagnose, analyse results, use surgical and other work related equipment, give medication as well as monitor patients' condition to ensure recovery. They sensitize the people on the outbreak of any disease and provide early warning on threat to human health. The environment nurses operate and their activities drive their information needs. A combination of their information needs and sources they consult constitute their information seeking behaviour. Nurses Information needs and seeking behaviour may depend on the years of experience, age, educational qualification and their working environment. 
However, the study which determined the information needs and seeking behaviour of nurses at Rivers State University Teaching Hospital shows that nurses' information needs include drugs therapy, diagnostic, and patients' management. The factors that motivate their information seeking include their working environment, patients care, professionalism and personal development. To satisfy their curiosity, they consulted different sources of information including colleagues, internet and textbook. They had a negative perception about library and information services. Inadequate information resources in the library, inadequate information retrieval skills and closed access were some the challenges they faced when seeking for their information needs. However, they suggested training of nurses and provision of standard library for the nursing. It can therefore be concluded that availability of information and skills to access the needed information would motivate nurses to seek for their information needs.

\section{Recommendations}

Based on the findings of the study, it was recommended that:

1. Libraries should provide adequate information that will meet the information needs of nurses.

2. Information providers should not hoard information.

3. Nurses should acquire ICT skills, especially information literacy skills to enable them retrieve relevant information from the internet and databases

4. Nurses should see the library as the most reliable place where the most desirable information can be sought.

5. Nurses should also access information from the databases such as HINARI, Pubmed, etc as only relevant information are contained in them.

\section{References}

Adebayo, O.J., Michael.J.A.\&Akole, B.O. (2017) Information needs and seeking behaviourof medical students at the college of medicine, University of Ibadan, Nigeria. Journal of Applied Information Science and Technology, 10 (2) (2017), 49-62. Retrieved from https://www.researchgate.net/publication/319490492.

Anyanwu, E.U., Oparaku, D.C. \& Benson, O.C. (2016) Meeting the information needs of nurses for effective healthcare delivery in Nigeria: a case study of federal medical centre, Owerri, Imo State. Library Philosophy and Practice (e-journal). Retrieved from http://digitalcommons.unl.edu/libphilprac/1427.

Asl, E. A, ,Ghasemi A. 1. H., Gharibvand, B. S., \&Malehi, A. S.(2017) surveyed the information seeking behavior and information needs of nurses in Ahvaz hospitals affiliated to Jundishapur University of medical sciences in using Up-To-Date database. BMJ Open, 7(0), A1A7

Baro, E. \&Ebhomeya, L. (2013), "Information needs and seeking behaviours of nurses: A survey of two hospitals in Bayelsa State, Nigeria", Health Education, 113(3), pp. 183-195.

Bruce C (2014) Information experience: approaches to theory and practice. Bingley, England: Emerald Group.

Campbell L (2017) The information-seeking habits of Architecture faculty. College and Research Libraries ,761-773.

Case, D. O. \& Given, L. M. (2016) Looking for information: a survey of research on information seeking, needs, and behavior, 4th ed. Bingley, England: Emerald Group. 
Chandel, A. S. \&Saikia, M. (2012) Challenges and opportunities of e-resources. Annals of Library and Information Studies 59, 148-154.

Eftekhar, Z. \&Hayati, Z. (2016) Coping with information resources: identifying, searching, accessing, evaluating and using information in academic libraries. International Journal of Information Science and Management 14(1), 1-11.

Igwela, J.N. \&Nsirim, O. (2018) Library and information services for national security and fight against insurgency. A paper presented at the $56^{\text {th }}$ national conference/AGM of the Nigerian Library Association, Ogun. Compendium of conference papers.

Makinde, O.B., Jiyane, G. \&Mugwisi, T. (2019) "Factors and challenges affecting the information-seeking behavior of science and technology researchers"Library Philosophy and Practice (e-journal). fromhttps://digitalcommons.unl.edu/libphilprac/2575

Marshall, J., Morgan, J., Klem, M.. Thompson, C., Wells, A., (2014) "The value of library and information services in nursing and patient care". The Online Journal of Issues in Nursing, 19 (3), 275-285.

Muokebe, B., Enzeani, U. \&Nwankwo, N.G. (2018) Information need and seeking behaviour of practising nurses in Nigeria; the case of our lady of lourdes hospital Ihiala. Library Philosophy and Practice. Retrieved from https://search.proquest.com/docview/2163340797/43F5DDB8FF3D42C1PQ/4?accountid=16686 $\underline{0}$

Nwagwu, W.E. \&Oshiname, R. (2009) Information needs and seeking behaviour of nurses at university college hospital university of Ibadan. African Journal of Library, Archives and Information Science, 9(1), 25-38.

Ford N (2015) Introduction to information behavior. London: Facet.

Ota, H., Azuma, M. \& Nishimura, H. (2017) Factors influencing information-seeking behavior in continuing education of nurses in Japan. Journal of Nursing and Health Care (JNHC) , 4(2), 3842

Popoola, S.O. (2008). The use of Information Sources and Services and its Effects on Research Output of Social Scientists in Nigerian Universities. Library Philosophy and Practice. Retrieved from http://www.webpages.uidaho.edumbolin /popoola.htm

Saha, P. \& Jena, P. (2020) Information needs and seeking behaviour of private hospital nurses of Bhubaneswar, Odisha: A comparative study. Library Philosophy and Practice. from https://digitalcommons.unl.edu/libphilprac/2575

Spring, C. (2010) Sources of Information. USA, Federation of Texas A \&M University Mothers' Clubs.

Wanyingi, C. (2018) Information needs and seeking behaviour of nursing and clinical students in medical libraries in Aga Khan University. Published master dissertation. 